\title{
Searle: significado y referencia en los discursos de la ciencia
}

\author{
ANGÉLICA RODRÍGUEZ ORTÍZ* \\ Universidad Autónoma de Manizales (Colombia) \\ amrodriguez@autonoma.edu.co \\ FREDDY SANTAMARÍA VELASCO** \\ Universidad Pontificia Bolivariana (Colombia) \\ freddy.santamariave@upb.edu.co
}

\begin{abstract}
Resumen
Algunos nombres usados en nuestro lenguaje no se aplican efectivamente a nada ni nadie si son tomados de forma literal, pues carecen de referente. En términos searleanos, su significatividad no depende que puedan dar cuenta o no de ejemplares en el mundo; su significatividad se "mide" en el uso de ellos en tal o cual discurso, en medio de explicaciones o caracterizaciones forjadas por reglas, pues hablar un lenguaje es tomar parte activa en una conducta compleja gobernada por reglas. Este artículo sustenta cómo en la filosofía de Searle la significatividad de los discursos, entre ellos los de la ciencia o los de la ficción, se logra en la emisión de actos ilocucionarios que hacen posible la invención de mundos cargados de significados, aun cuando estos carezcan de referencia directa.
\end{abstract}

Palabras claves: Significatividad, referencia, actos ilocucionarios, mundos posibles.

\section{Searle: meaning and reference in the speeches of science}

\begin{abstract}
Some names in our language are not indeed applied to anything or nobody if they are taken literally, because they lack their referent. According to Searle, names' significance does not depend on how they can give account or not of world samples; their significance "is measured" in the use of them in this or that speech, amid explanations or characterizations forged by rules, because to speak a language it is to take active part in a complex rule-governed behavior. This article supports how in the philosophy of Searle meaningfulness of speeches, including those of science or fiction, is achieved in the issuance of illocutionary acts that make possible the invention of worlds full of meanings, even when they lack direct referent.
\end{abstract}

Key words: significance, reference, Illocutionary acts, possible worlds.

Licenciada en Filosofía y Letras, así como Magíster en Educación por la Universidad de Caldas. Doctoranda en Filosofía por la Universidad Pontificia Bolivariana (Medellín, Colombia). Líder y Docente del programa de Maestría en Enseñanza de las Ciencias de la Universidad Autónoma de Manizales. Investigadora del grupo: SEAD-UAM en la línea de Actores y Contextos.

** Doctor en Filosofía y Letras por la Universidad Pontificia de Salamanca (España). Doctor en Filosofía por la Universidad Pontificia Bolivariana. Miembro de la Sociedad Colombiana de Filosofía (SCF). Actualmente profesor de la Universidad Pontificia Bolivariana.

Recibido: 11/Enero/2017 - Aceptado: 2/Marzo/2017 


\section{Introducción}

Referencia, nombre y significado han sido en la filosofía analítica motivo de discusión ${ }^{1}$. Para algunos estudiosos del lenguaje, el significado de una palabra o nombre está ligado al referente. Sin embargo, la significatividad de un término no siempre evoca un referente. Luego del giro lingüistico, iniciado por Wittgenstein en sus Investigaciones Filosóficas, el estudio del lenguaje se remonta a la pragmática del mismo. El uso de los enunciados nos remite a invocar la significatividad en la aceptabilidad o no de tales nombres dentro de un juego de lenguaje (Wittgenstein, 1988). Y los juegos del lenguaje simplemente se dan en el seguimiento de las reglas que regulan los comportamientos verbales.

En los estudios de Searle, el lenguaje evoca, como lo planteó Wittgenstein, diferentes juegos que se evidencian en tales o cuales discursos. Cada discurso posee sus propias reglas y estas permiten a los hablantes alcanzar la significatividad de los términos usados en los discursos proferidos. Eliminar la ambigüedad y delimitar el significado según el contexto implica al hablante superar las intuiciones y dominar las reglas de la conducta verbal. La significatividad de un nombre no depende de su correspondencia con el objeto nombrado, pues los nombres no funcionan como etiquetas que se adbieren a los objetos, sino que son "movimientos" aceptados dentro de un juego del lenguaje. Los hablantes que deciden jugar un juego u otro, según el discurso, están obligados a conocer, usar y dominar las reglas del mismo.

Las diversas caracterizaciones lingüísticas realizan análisis sobre las expresiones que usamos a diario en los procesos comunicativos; se exploran taxonomías sobre cada uno de los términos que componen nuestros enunciados en aras de comprender el significado de estos en las expresiones que conforman. Asimismo, podemos encontrar taxonomías lingüísticas en el discurso, diferenciando en estas los discursos explicativos y los discursos caracterizadores en aras de proveer de significado los enunciados que expresamos en la comunicación. Sin embargo, ni las caracterizaciones, ni las taxonomías dan cuenta del significado de los nombres usados en un contexto $\mathrm{X}$ o $\mathrm{Y}$, es decir, tales estudios se quedan en los significados literales y su clasificación según la función del término dentro del enunciado; no dan cuenta del significado del enunciado como un todo y mucho menos del discurso.

1 El presente artículo constituye un apartado de la investigación que se está realizando para la tesis de doctorado en Filosofía en la Universidad Pontificia Bolivariana y pertenece al proyecto de investigación: Naturalez̧a biopragmática de la moral. Lenguaje y mente como elementos necesarios de la institución moral. Una investigación cuya metodología está enraizada en el método analítico, desde el análisis lingüístico de la obra de John Searle y otros autores de la filosofía de la mente y del lenguaje. 
Ahora bien, contrario a lo sustentado por el positivismo lógico, los enunciados del discurso científico moderno no son propiamente enunciados con referencias de contrastación empírica. La mayoría de los enunciados de las teorías de la física cuántica, o de los procesos de la combustión en la química moderna, por ejemplo, carecen de referente; sin embargo, no por ello carecen de sentido.

Los términos sin referencia directa, usados en los enunciados de la ciencia, son juicios de hecho, cuyo significado es dado en el uso del lenguaje y en las convenciones de la comunidad que los usa para dar explicaciones a tales fenómenos físicos. En otras palabras, parte de los términos usados en los enunciados básicos, de las denominadas ciencias duras, no soportan un análisis referencial del significado si este depende de la contrastación empírica. Pese a ello, son enunciados que permanecen como fundamento de teorías, puesto que permiten la comprensión de los fenómenos físicos. Dichos enunciados - considerados "objetivos"están sustentados en supuestos hipotéticos que no logran pasar la prueba del criterio de demarcación, con lo cual, escapan a la lógica tradicional referencialista de la significación basada en la contrastabilidad de enunciados empíricos. Tales enunciados carecen de referencia más no de significado. En este sentido un juicio de hecho como "la partícula de Higgs permite explicar el origen de la masa" ha sido un enunciado sobre el cual se edifican teorías de la física, aun cuando, "partícula de Higgs" no es otra cosa que un nombre de "ficción", pues es un término que no cumple con los criterios de la ciencia empíricamente verificable, se respalda en supuestos hipotéticos para generar otras explicaciones.

La realidad que evocan términos como "flogisto" "éter", "átomo", "partícula de Higgs", entre otros, es similar a la realidad de términos como "unicornio", "sirena" o "minotauro". La diferencia lingüística entre tales términos radica en el discurso que componen; ya que, mientras el primero hace parte del discurso de "ficción" de la ciencia, los últimos constituyen el discurso de literatura de ficción.

El presente artículo pretende mostrar cómo los enunciados de "ficción" que abundan en la ciencia, pese a que carecen de referencia, sustentan su significado en el uso del lenguaje especializado dentro de una comunidad específica. La teoría de la física cuántica, la teoría del modelo atómico, los procesos de combustión y oxidación, son ejemplos de

2 Se toma el término "ficción" para hacer referencia a aquellos términos que carecen de referente empírico. En el caso de la ciencia, aquellos términos que explican realidades hipotéticas a partir de supuestos. Términos que pertenecen a un discurso especializado y que no tienen referente en el mundo real, pero permiten entender los fenómenos naturales.

VERITAS, No 36 (Abril 2017) 
discursos de la ciencia que se enmarcan en el uso de términos sin referencia. Sus enunciados hacen posible la comprensión de los fenómenos físicos. Términos como "flogisto", "oxígeno", "átomo", entre otros, constituyen los enunciados básicos de las teorías científicas; enunciados cuyo sujeto se manifiesta a través de tales términos sustentan paradigmas y modelos científicos que han sido construidos bajo modelos o bien verificacionistas, o bien falsacionistas. Teorías que en su mayoría continúan vigentes, pese a que sus enunciados no logren pasar las pruebas del análisis del lenguaje en el criterio de demarcación o bien verificacionista, o bien falsacionista sustentado en la referencia.

\section{El discurso de "ficción" en la ciencia}

El discurso de la ciencia ha sido, por excelencia, el foco de los análisis de los estudiosos del lenguaje. Los planteamientos de la lógica referencial, centrados en el criterio de demarcación, permiten analizar los significados de los enunciados básicos de la ciencia; un análisis al cual no escapan ni el verificacionismo clásico de Carnap y Ayer (1983) ni el falsacionismo de Popper. Teorías que, pese a las diferencias que convocan, convergen en su pretensión por demostrar la objetividad y la significatividad referencial de los enunciados básicos de la ciencia.

Si el problema [de la veracidad] se refiere a una proposición que afirma algo respecto de una percepción actual, por ejemplo: "En estos momentos veo un cuadro rojo sobre un fondo azul", entonces la proposición puede probarse directamente por medio de mi percepción actual [... Por su parte] una proposición $\mathrm{P}$ que no es verificable directamente sólo puede ser verificada mediante la verificación directa de otras proposiciones deducidas de $\mathrm{P}$ y de otras proposiciones ya verificadas (Carnap, 1998: 7-8).

El problema que convocan Carnap y Ayer es el de la significatividad referencial ligada al problema de la verdad. Para Carnap, la verificación directa determina el significado y el valor de verdad del enunciado. Sin embargo, hay enunciados que no cumplen con el criterio verificacionista, y aun así poseen significado. Tal vez por ello, Saer expone: "El rechazo escrupuloso de todo elemento ficticio no es un criterio de verdad. Puesto que el concepto mismo de verdad es incierto y su definición integra elementos dispares y aun contradictorios, es la verdad como objetivo unívoco del texto y no solamente la presencia de elementos ficticios lo que merece, cuando se trata del género biográfico o autobiográfico, una discusión minuciosa" (Saer, 1997: 10). 
La verificación directa y deducida nos remite, no solo al problema de la verdad, sino del significado del enunciado mismo. La verificación de principio se convierte en el principio del significado del enunciado. En palabras de Carnap, la posibilidad de deducción de proposiciones perceptivas de los enunciados de la ciencia convoca la posibilidad de verificación. De igual forma, la objetividad crítica de Popper, plantea con su principio de refutabilidad una contrastación con los hechos empíricos: "[...] podría describírsela como la teoría del método deductivo de contrastar, o como la opinión de que una hipótesis sólo puede contrastarse empíricamente -y únicamente después de que ha sido formulada" (Popper, 1981: 153), lo que reclama un fundamento en la experiencia. Es decir, ambas posturas se comprometen con el estudio de los enunciados desde la contrastabilidad empírica de los enunciados básicos de la ciencia, pese a que ambas sostienen formas diferentes de hacer ciencia.

Sin embargo, como se ha esbozado, el discurso de la ciencia, en su mayoría, no resiste el análisis de contrastabilidad perceptual en su forma directa; algunos enunciados de la ciencia ni siquiera pueden ser verificados en las deducciones derivadas, pues su fundamento está basado en supuestos hipotéticos. En el proceso de oxidación, por ejemplo, el término "oxígeno" fundamenta los enunciados de la teoría no por contrastación del término "oxígeno" con su objeto de referencia, sino por los enunciados derivados que hacen alusión a los efectos de este elemento químico en la oxidación. No hay una relación directa nombre/cosa. El sustantivo "oxígeno" no actúa como etiqueta de objeto alguno.

Los enunciados básicos, cuyo sujeto no posee referencia, acaban por ser hipótesis basadas en supuestos. Hipótesis sobre las que se construyen teorías, en las cuales el principio de contrastabilidad deja de ser la garantía en el significado. ¿Qué otorga garantía de significado en las teorías cuyo sustento lo brindan de términos como "oxígeno" o "átomo”? ¿Qué garantiza que los enunciados que sustentan en la química moderna los procesos como la combustión sean objetivos y se constituyan en modelos y paradigmas de teorías que explican los fenómenos físico-químicos del mundo, si no hay una referencia que lo haga posible? ¿De qué depende el significado de los enunciados de la física cuántica, si los enlaces de moléculas y las uniones atómicas no son referenciables empíricamente? El significado del discurso en la ciencia, en los ejemplos citados, no depende del referente empírico; razón por la cual, debe existir otra forma de lograr la significatividad y esta es: a través del uso del lenguaje. El dominio de las reglas en un juego del lenguaje específico permite a los hablantes dotar de significado los discursos específicos.

El criterio de demarcación tanto verificacionista como falsacionista centró su atención en el análisis lógico de los enunciados de la ciencia. Los 
ejemplos que exponen una y otra teoría llevaban a revisar el valor de verdad de los enunciados en términos de la referencia de los mismos. Sin embargo, cabría preguntarse, ¿por qué los enunciados de la teoría del flogisto o de la oxidación, por ejemplo, no fueron expuestos en tales análisis, si los términos que las sustentan no son términos referenciables? Pese a ello, tales teorías han permitido comprender los fenómenos físicoquímicos, y algunas continúan vigentes.

La teoría del flogisto, expuesta por Becher en 1667 fue considerada, por casi un siglo, el paradigma para la comprensión del fenómeno de la combustión. Luego de que, el químico alemán, Stahl la defendiera y reafirmara dicha teoría brindó las bases para comprender fenómenos como la fluidez, la combustión y la inflamabilidad. El término "flogisto" era, entonces, el que permitía explicar tales fenómenos. Las teorías construidas con tales términos no carecían de significado pese a la falta de referencia de los mismos. La teoría del flogisto se mantuvo vigente por más de cien años y la comunidad científica usó los enunciados que contenían el término en pos de dar respuesta a los fenómenos en cuestión.

En la química moderna, la revolución científica de Lavoisier, presenta una nueva teoría para dar explicación a los fenómenos de la oxidación y la combustión; el término "flogisto" fue reemplazado por "oxígeno". Un término que, al igual que el anterior, carece de referencia, pero no de significado. Así pues, las teorías de la ciencia construidas bajo supuestos hipotéticos se enmarcan en enunciados, cuyos sujetos no evocan referente, pese a ello no carecen de significatividad. El significado de los enunciados de la ciencia, contrario a lo esperado por Carnap o Ayer, no está dado en términos de la referencia, sino en el uso del lenguaje aceptado por la comunidad científica.

En las caracterizaciones del discurso, los analistas del lenguaje han expuesto este problema en el marco de la literatura de ficción o de los juicios morales, puesto que los términos allí usados carecen de referencia, más no han abordado en sus estudios los enunciados de la ciencia, producto de supuestos hipotéticos. Razón por la cual, es igualmente válido preguntarse por la realidad que representan conceptos como "Macondo" o "Remedios la bella", o por las referencias de "bueno" o "malo", así como por los términos de la ciencia que carecen de referente. Cabría preguntarse, entonces, ¿por qué los enunciados de la ciencia que son producto de supuestos hipotéticos no han sido sometidos a tales análisis, como sí ha ocurrido con los discursos literarios y morales? ¿Cómo se le atribuyen significados de acuerdo al criterio de demarcación, o bien verificacionista o bien falsacionista, a los términos no referenciales de la ciencia, si estos poseen la misma realidad de "ficción" que los términos usados en el discurso literario o moral? 


\section{El significado en la pragmática del lenguaje}

El problema sobre significado y referencia fue abordado desde otra perspectiva a partir del denominado giro lingüistico. El planteamiento Wittgensteiniano permitió repensar el lenguaje en términos de juegos y discursos, en los cuales cada jugador está en la obligación de dominar las reglas. Un planteamiento que aterriza el análisis del lenguaje al uso del lenguaje ordinario y permite pensar nuevas lógicas en la comunicación; lógicas que son susceptibles de significatividad en la pragmática del lenguaje y que descarta la referencia como garantía de la objetividad y la significatividad de los enunciados.

En una línea similar se postulan los estudios del lenguaje de Austin y Searle, para quienes el lenguaje se convierte en actos, además de hacer posible la creación de nuevos mundos, nuevas realidades y nuevos significados. Para Searle, todo hablante competente está en la obligación de dominar las reglas del lenguaje y el significado de los términos está dado en el uso del lenguaje. Así cada discurso exige a los hablantes ser competentes en el seguimiento de las reglas para comprender los significados de los términos usados en cada enunciado proferido. Tanto el discurso de la literatura como el discurso científico tienen un juego de reglas que le es propio al juego del discurso especializado, y sobre el cual se develan los significados.

La teoría de los actos de habla de Searle permite iniciar la búsqueda del significado de los enunciados en la pragmática del lenguaje y salirse del marco de la referencia. Elementos como la intencionalidad y las funciones de estatus le permiten al autor, plantear el significado de los discursos solo en el uso convencional que le otorga la colectividad a los términos que los componen.

En palabras de Kuhn, siguiendo los planteamientos searleanos, podríamos decir que, cada comunidad científica usa un lenguaje especializado que impone el paradigma. Los científicos de una determinada comunidad están en la obligación de dominar las reglas del discurso que circunda en el paradigma. Así, hay problemas que no pueden enunciarse de acuerdo con las herramientas conceptuales e instrumentales que proporciona el paradigma (Kuhn, 2004) y solo los problemas que competen al paradigma serán abordados con las herramientas conceptuales que el paradigma posee. Es decir, el lenguaje usado por la comunidad científica dentro de un paradigma, permite realizar enunciados explicitos de leyes científicas y sobre conceptos y teorias científicas y el significado está dado en términos de la aceptabilidad de la comunidad científica de cada paradigma.

Cada comunidad científica tiene la responsabilidad de usar el lenguaje dentro del paradigma para dar solución a los enigmas que allí surgen. En 
la ciencia, el lenguaje aceptado en las teorías no llega a ser contrastado con los hechos, aun cuando den explicaciones sobre ellos. "Para ser aceptada como paradigma, una teoría debe parecer mejor que sus competidoras; pero no necesita explicar y, en efecto, nunca lo hace, todos los hechos que se puedan confrontar con ella" (Kuhn, 2004: 43). Muchas de las contrastaciones son con fenómenos secundarios, más no con referentes directos de los términos que fundamentan las teorías. En otras palabras, la significatividad de los discursos científicos no depende del referente de los nombres, sino del uso del lenguaje aceptado en el discurso de la ciencia.

Los juegos, las reglas, la pretensión, las funciones de estatus y los actos ilocucionarios se convierten, para Searle en una serie de herramientas para crear significados en cada discurso; además de hacer posibles nuevos mundos cargados de significados construidos intencionalmente. Mundos como la realidad social, los cuales acaban por ser familiares; mundos, que pese a ser "ficticios", están cargados de significatividad.

\subsection{El problema: nombre, objeto y referencia}

Los escritos de Platón sobre el lenguaje develan la inminente preocupación por el tema que plantea la relación entre el nombre y la cosa. Para el Sócrates platónico, la pugna entre significado por semejanza y convención fue un tema que convocó a la elaboración de su diálogo Crátilo. No es fácil aceptar que el significado de un nombre asignado a la cosa sea producto del uso que damos al lenguaje; no resulta hacedero consentir que los nombres se crean intencionalmente en la pragmática del lenguaje, y que ellos acaban por constituir nuevas realidades. Por tal motivo, es mayormente plausible asentir una relación directa entre el nombre y la cosa, como lo expuso Sócrates y como posteriormente lo retomaron algunos filósofos analíticos.

¡Claro que yo, personalmente, prefiero que los nombres tengan la mayor semejanza posible con las cosas! Pero temo que, en realidad, como decía Hermógenes, resulte «forzado» arrastrar la semejanza y sea inevitable servirse de la convención, por grosera que ésta sea, para la exactitud de los nombres (Platón, 1987: 435c).

El planteamiento socrático, tal vez sea la primera aproximación al problema de la referencia; su propuesta de una teoría del significado, en la semejanza que se presenta en relación nombre/cosa, nos plantea un primer esbozo del tema en cuestión. Sin embargo, pese a la radicalidad de la postura socrática para trabajar la teoría por correspondencia en la relación nombre/cosa, queda claro que esta no excluye la posibilidad de considerar 
la significatividad de los nombres de "ficción", ya que se da en una relación de semejanza del nombre con la naturaleza de la cosa; por ello, aun cuando, nombres como "Remedios la bella", "Sherlock Holmes", en la literatura de ficción, o términos como "oxígeno" o "átomo" en la ciencia moderna, no tengan un objeto en el mundo que los represente, sí hacen alusión a la naturaleza de la cosa nombrada. Es decir, a la naturaleza del personaje que ha sido creado para dotar de significado, o bien a un nuevo mundo, y en el caso de la ciencia, a la naturaleza del fenómeno estudiado.

Ahora bien, Frege (2005) y Russell (1966) fueron autores determinantes en el inicio de la discusión sobre la significatividad de los nombres de "ficción". Tanto las teorías de la referencia directa o verificacionista de Carnap como las teorías descripcioncitas de Frege y Russell ${ }^{3}$ han sido para los estudios posteriores, es decir, para la teoría de los juegos del lenguaje de Wittgenstein, así como para la de actos de habla, de Searle, y para las teorías causales de la referencia, expuestas por Kripke ${ }^{4}$ y Putnam; ya que estos últimos se han valido de los trabajos de los primeros autores, bien sea para apoyar, complementar, refutar o negar por completo sus supuestos.

Preguntarnos qué garantiza que términos como "átomo" u "oxígeno" tengan significado nos remite a Frege, quien distinguió entre el sentido (Sinn) y la referencia (Bedeutung) de un nombre. Para Frege, este tipo de nombres no señalan a ningún individuo, no cuentan con una extensión, pero sí con una intensión ${ }^{5}$ (unas descripciones) que sostienen el nombre. $\mathrm{Y}$ eso hace que pese a que no tengan referencia sí posean un significado.

A diferencia de Frege, quien considera que este tipo de nombres tienen claramente un sentido, puesto que tienen una intensión y ella es suficiente para salvaguardar la significatividad de dicho nombre, Russell piensa que todos los enunciados que contienen "nombres" de "ficción" no son verdaderos nombres propios sino meras descripciones definidas abreviadas, ya que no

3 La teoría descripcionista de Russell planteó que en el caso de enunciados como "el actual rey de Francia es calvo" carece de significado, puesto que no denota ningún objeto, ya que, actualmente en Francia no hay un rey. Sin embargo, la teoría de Meinong ha postulado que es posible considerar entidades no existentes de las que podemos hablar y en ese caso, podríamos decir, que los entes de ficción en la ciencia que permiten explicar diferentes fenómenos del mundo, como "partícula de Dios" puede ser una de estas entidades.

4 Sin embargo, como plantea Santamaría, siguiendo a Kripke: "Las descripciones no son garantía de identificación del individuo, pues la mayoría de las veces los hablantes no cuentan con una descripción identificadora como respaldo del nombre que usan" (Santamaría, 2011: 409).

5 Se sugiere, entonces, que tales nombres son comprensivos, su significado es comprensivo, dado en el discurso al describir un conjunto de propiedades, o desde el conjunto de unidades semánticos del nombre mismo, como unidad léxica.

VERITAS, No 36 (Abril 2017) 
designan nada en absoluto. Los nombres, para Russell, "los verdaderos nombres propios" o aparentes "nombres" de "ficción", tienen el poder de mostrar (enseñar) el individuo portador del nombre, el ejemplar, o al objeto al que se refiere. Si no hay referente (extensión, ejemplares) como es el caso de los aparentes "nombres" de "ficción" que usamos en los discursos de la ciencia, tendremos que decir — según Russell— que no son de ningún modo verdaderos nombres (Russell, 2005).

Los llamamos nombres porque, según el autor inglés, no hacemos un análisis correcto de nuestros enunciados. Razón por la cual, estos errores son fruto de la ambigüedad de nuestro lenguaje. Lo que en última instancia le preocupa a Russell es que el lenguaje, si pretende ser riguroso (científico), debe hablar sólo de aquello de lo que pueda dar cuenta, esto es, se debe contar con los ejemplares nombrados.

Un lenguaje lógicamente perfecto es aquél en el que cada nombre cuenta con su referente, en pocas palabras: en donde todo lo nombrado existe. "La lógica (...), no tiene que admitir un unicornio en mayor medida que pueda hacerlo la zoología (...). Decir que los unicornios tienen una existencia heráldica o en la literatura o en la imaginación es una evasión sobremanera lastimosa y mezquina" (Russell, 2005: 52). Pese a ello, seguimos usándolos.

Cabría preguntarse, entonces, ¿por qué Russell no puso en análisis el concepto "oxígeno" que sustenta las teorías de la oxidación y la combustión en la química moderna, si la teoría ya estaba vigente y "oxígeno" es un término con referencia similar a "unicornio? No admitir al unicornio desde los parámetros de la lógica le llevaría a no admitir tampoco el término "átomo" o el término "oxígeno", puesto que las realidades de los tres términos están basadas en supuestos y su significatividad está enmarcada en el discurso en que se usan.

Pues bien, con relación al punto a saber: al problema de la referencia, el filósofo Nelson Goodman, en su libro De la mente y otras materias, nos advierte que la referencia más que ser definida, debe ser explicada, distinguiendo y comparando las múltiples formas en que ella puede aparecer (Goodman, 1995: 94). Esto quiere decir que debemos primero intentar explicar, describir y comparar las diferentes rutas que tiene la referencia para presentarse en los diferentes contextos y discursos, como son los discursos literales o los discursos no-literales o de "ficción" de la ciencia. Para el autor norteamericano:

Los mundos de ficción, de la poesía, de la pintura, de la música o de la danza y los de las otras artes están hechos en gran medida de mecanismos no literales, tales como la metáfora, o por medios no denotativos, tales como la ejemplificación y la expresión. Y en esos mundos se acude también, con 
frecuencia, a imágenes, sonidos, gestos o a otros símbolos pertenecientes a sistemas no lingüísticos (Goodman, 1990: 140-141).

De este modo, tenemos que, nombres como "Don Quijote" o "Unicornio" son similares a "oxígeno", "flogisto" o "átomo", puesto que no se aplican efectivamente a un objeto o una persona si son tomados literalmente. La referencia de tales nombres va más allá del objeto que representa. Razón por la cual, la analogía es una herramienta fundamental a la hora de brindar explicaciones en gran parte de las teorías de la ciencia.

La significatividad de tales nombres no depende de que puedan dar cuenta o no de ejemplares; su significatividad en términos wittgensteinianos se "mide" por el uso de ellos en tal o cual discurso, esto es, en la aceptabilidad que le demos o no a tales nombres dentro de un juego de lenguaje, pues, todos los términos que usamos, los usamos de acuerdo al contexto en el que son proferidos. En las concepciones del lenguaje, tanto de Wittgenstein como de Searle, el problema se resuelve al comprender que la "ficción", tanto en la literatura como en la ciencia, es un juego cualquiera, como muchos, entre los juegos del lenguaje; es decir, un juego más dentro de lo que podemos llamar las "prácticas humanas ${ }^{\prime 0}$. Un juego regulado y constituido por reglas.

\subsection{La significatividad en los juegos del lenguaje}

En las Investigaciones filosóficas, Wittgenstein recusa del atomismo lógico, pues si antes el significado de un nombre era el objeto al cual se hacía referencia, ahora se inicia una bifurcación que apunta hacia el uso ordinario del lenguaje, es decir, el significado de un nombre no se da en términos de la necesaria correspondencia con el objeto nombrado (nombreobjeto), sino en el uso de ese nombre en un lenguaje, en un discurso concreto y determinado.

Para Wittgenstein, la definición ostensiva puede explicar el significado, si de antemano tenemos claro cómo hay que usar tal o cual palabra en el lenguaje, cosa que Russell no admitió, puesto que la definición ostensiva nos lleva a mostrar deícticamente, es decir, a poder señalar tal o cual objeto de referencia. Sin embargo, no se puede decir que nombrar o designar sea señalar ostensivamente, ya que, si tomamos la definición ostensiva como método fundamental de significación de las palabras, advierte Robert J. Fogelin, hemos fracasado, pues "la actividad de dar una definición ostensiva

6 Este punto lo trata con profundidad Santamaría (2007) en el libro Nombres, significados y mundos, especialmente en el capítulo dedicado a Wittgenstein y el problema del significado de los nombres sin referencia.

VERITAS, No 36 (Abril 2017) 
tiene sentido sólo en el contexto de una estructura lingüística previamente establecida" (Fogelin, 1995: 18).

Este tipo de nombres, que surgen como supuestos hipotéticos, aparecen como nombres de "ficción" usados en el discurso científico; se refieren a fenómenos físicos, de manera figurada y simbólica; fundamentan las teorías de la materia, la oxidación o la combustión, entre otras., creando realidades hipotéticas. Fenómenos que pueden ser percibidos en su manifestación del efecto, por simples conjeturas, más no por el método clásico de la comprobación empírica. Nombres como "átomo" y "oxígeno" carecen de referente directo, pero sustentan a través de conjeturas las explicaciones físico-químicas sobre la materia, la oxidación y la combustión, en términos de sus efectos perceptibles. En otras palabras, algunos nombres (palabras) pueden denotar aquello a que se refieren, pero es evidente que algunos nombres (palabras) no denotan nada, pues no cuentan con ejemplares; pese a ello, permiten explicar fenómenos, como ocurre en la ciencia moderna, ya que pueden referirse, en palabras de Goodman, de un modo metafórico o figurativo al fenómeno.

Así pues, proferir enunciados metafóricos o figurativos no es sólo un recurso retórico, sino un mecanismo creativo y válido en la comunicación, no solo cotidiana, sino en la ciencia. Los términos de "ficción", los términos que no tienen referente, pertenecen a un discurso especializado en la comunicación y en este adquieren su significado. El uso de ciertos términos carentes de referente, pero no de significado, Searle lo postulará como un modo de crear una realidad social, y los enunciados no referenciales usados en la ciencia hacen parte de una realidad que se institucionaliza en el uso de las reglas. Una realidad hipotética aceptada por la comunidad científica, la cual permite comprender parcialmente los fenómenos que aún son enigma en el universo.

De este modo, en los discursos de "ficción" de la ciencia moderna, así como en otros discursos, se evidencia el uso de lenguajes no literales, que lejos de ser un artificio se convierten en una herramienta para brindar explicaciones científicas o imaginarias, según sea el caso. El uso del lenguaje permite hacer que nuestros términos tengan "pluriempleo", con los cual se da paso a la re-creación e invención de "mundos", de "realidades" de "ficción" que permiten de algún modo la comprensión de nuestro mundo. Basta con revisar las teorías de la física cuántica para identificar nuevas lógicas de comprensión de nuevas realidades que no se someten al criterio de demarcación referencial.

En tal sentido, la significatividad de un nombre no depende de su correspondencia con el objeto nombrado; como lo quisieron plantear Platón o Russell. Los nombres no funcionan como etiquetas que se adbieren a los objetos, 
como lo expuso Goodman. Razón por la cual, pensar el lenguaje en términos cartográficos, es decir, concebir el lenguaje-como-imagen del mundo, "no sirve para explicar cómo se aprende o se entiende el lenguaje" (Rorty, 2001: 270).

Si entendemos que la significatividad de un nombre depende del uso, es decir, de la "aceptabilidad" de los aspectos, los rasgos y las descripciones que de algún modo se consideran más importantes, podremos aceptar que los nombres de "ficción", usados en el discurso de la ciencia, son perfectamente significativos, pues no son una imagen o un espejo de la naturaleza, sino que son "movimientos" aceptados dentro de un juego del lenguaje. Un juego creado en el marco de las reglas que se institucionalizan para crear realidades sociales. Para Rorty la significatividad de estos nombres depende del cómo se concibe la verdad, esto es, si se entiende como afirmabilidad avalada o como espejo de la naturaleza. Por esto mismo, el problema de concebir la verdad como "correspondencia con la realidad" y no como "afirmabilidad avalada", equivale a ver el lenguaje como una imagen y no un juego regido por reglas, pero las teorías de la ciencia moderna no son un espejo de la naturaleza, ni pretenden serlo; para servir de explicaciones, el juego del lenguaje usado en el discurso de "ficción" de la ciencia exige a los hablantes la consideración del mismo como "afirmabilidad avalada".

\section{Referencialidad y significatividad en Searle}

Para Searle (1979, 1995 y 2010) ${ }^{7}$, los nombres que asignamos no son más que producto de nuestra intencionalidad. Así como las funciones y significado que le damos a los mismos. Los nombres de "ficción" hacen referencia a los personajes creados intencionalmente en el mundo literario, y los nombres de "ficción" usados en la ciencia, hacen referencia al mundo de hechos brutos que se manifiestan como fenómenos de la naturaleza, los cuales, aun cuando no son visibles permiten entender el mundo y dar cuenta de él.

Los nombres existen porque en el juego del lenguaje le hemos asignado tales funciones. Los nombres de "ficción" en la literatura existen porque el autor les asignó funciones; personajes y nombres acaecen en los

Tanto en su artículo sobre el lenguaje, de 1979, presentado en su texto: Expression And Meaning, como en los giros presentados en 1992 en Rediscovery of Mind, sobre la intencionalidad, luego de sus estudios de 1983, en Intentionality; así como en The Construction of Social Reality, y en su texto de 2010, Making the social World, el autor reitera que las funciones que asignamos a un objeto $o$ a un nombre las asignamos intencionalmente. En Making the social World el autor se atreve a proponer a las funciones de como el producto de la intencionalidad humana. Una perspectiva que plantea que el lenguaje es una cualidad derivada de dicho estado mental.

VERITAS, No 36 (Abril 2017) 
significados que les damos a través del uso del lenguaje. Asimismo, en la ciencia, los nombres de "ficción" han sido tal, porque las comunidades científicas han asignado intencionalmente funciones de estatus. La palabra "oxígeno" designa un elemento, al cual, si bien no vemos, le atribuimos existencia por conjeturas, y le asignamos funciones en las explicaciones de los fenómenos. En la teoría searleana la definición ostensiva, al igual que para Fogelin, se da en el contexto y según la estructura lingüística que se decida usar, para el caso, el contexto sería el ámbito del discurso científico, el cual a la larga acaba por ser una realidad creada por el discurso que intenta dar cuenta de la realidad de hechos brutos que acaecen. Un producto meramente social ${ }^{8}$. Por lo cual, si dudáramos del significado de los nombres de "ficción" dudaríamos de la existencia de teorías como la combustión o la oxidación y por ende de los fenómenos que representa.

Searle en su libro Actos de habla se preguntaba cómo es posible que cuando un hablante está ante un oyente y emite una secuencia acústica sucedan cosas tan importantes como: a) que el hablante quiera decir algo; b) que el oyente comprenda lo que se le quiere decir; c) que el hablante haga un enunciado, plantee un enunciado y emita una orden y el oyente la siga. Nosotros, a partir de estas mismas cuestiones, nos preguntamos: ¿Cómo puede un hablante proferir un discurso, bien sea literal o ficticio, que sea comprendido por su oyente? ¿Cómo puede un hablante comunicar (significar) algo diferente de lo que propiamente ha dicho literalmente? Esto es, ¿cómo se deja de lado la idea de correspondencia, la idea del mundo-como-imagen para pasar del significado literal al significado connotativo de los enunciados? ¿Cómo logra el uso de los nombres de "ficción" crear teorías para explicar un mundo de fenómenos físicos no visibles? ¿Cómo se construyen significados en la ciencia a partir del uso de términos carentes de referente?

Los anteriores interrogantes nos llevan a examinar el giro lingüístico que plantea Searle al concebir la referencia como un acto de habla. Las expresiones referenciales definidas apuntan a cosas particulares; responden a las preguntas: ¿quién?, ¿qué?, ¿cuál? Es por su función que se conocen las expresiones referenciales, y no por la forma gramatical superficial o por la manera de realizar su función (Searle, 1980). Las expresiones referenciales no implican la concepción de que los nombres o las expresiones, según sea el caso, tengan necesariamente una referencia. "Al contrario- plantea

$8 \quad$ En Searle, "se puede reconocer un giro lingüístico pragmático, pues su análisis del lenguaje involucra los enunciados de la ciencia y la búsqueda de la verdad, y los enunciados de valor que evalúan hechos, acciones u otros enunciados, dentro de un marco social que considera al lenguaje como institución que permite la construcción de la realidad social" (Rodríguez, 2015: 220). Un giro que permite un análisis del significado en el uso del lenguaje. 
el autor- la referencia es un acto de habla, y los actos de habla los realizan los hablantes, no las palabras por sí mismas. Decir que una expresión hace referencia (predica o asevera) es en mi terminología o bien un sinsentido, o bien una abreviatura para decir que la expresión es usada por los hablantes para hacer referencia (predicar, aseverar, etc.) [...]" (Searle, 1980: 15).

El acto de habla, específicamente un acto ilocucionario como la aserción nos remite a las expresiones referenciales en el uso del lenguaje que hace el hablante. El indicador de la fuerza ilocucionaria es el que nos indica la referencia que emite el hablante con un nombre o con una expresión. Searle deja en claro que en el uso del lenguaje se puede hacer referencia tanto a los particulares como a los universales "Everest", "esta silla", "el color rojo" o "la embriaguez"; aun cuando, los universales no tienen un referente en el mundo. Cuando se emite el nombre "frutas" no podemos encontrar un referente de este nombre, de la misma manera que podremos encontrar el referente del nombre "naranja". Sin embargo, en el uso del lenguaje los hablantes saben a qué hace referencia la expresión "esto es una fruta". Con algunos de los términos usados en la ciencia ocurre igual, el término "átomo" carece de referencia, pero los hablantes tienen claro el significado de la expresión "esta mesa está compuesta por átomos".

De acuerdo con lo anterior, para Searle la referencia como acto de habla implica tomar parte de una práctica bumana gobernada por reglas. Por tal razón, tenemos que los enunciados que contienen nombres de ficción y que los reconocemos como parte de la literatura universal o del discurso de la ciencia, al hacer parte de una práctica humana, de una construcción social también están gobernados por una serie de reglas. Los términos del discurso científico, están gobernados por un juego de reglas, las cuales a su vez regulan las prácticas de sus construcciones de teorías y en las cuales se halla el significado de los enunciados. Hablar un lenguaje, desde la taxonomía realizada por Searle, consiste en realizar actos de habla, actos tales como hacer enunciados, dar órdenes, hacer preguntas, hacer promesas, dar las gracias, etc., regidos todos ellos bajo ciertas reglas para el uso de los elementos lingǘsticos y orientados en su diferenciación por la intencionalidad del hablante.

\section{Actos ilocucionarios y significatividad en los discursos}

Las palabras se constituyen en actos y estos actos tienen el poder de crear nuevas realidades; mundos cargados de significados. La razón fundamental de Searle para dedicarse al estudio de los actos de habla es, simple y llanamente, la siguiente: Toda comunicación lingüistica incluye actos lingüísticos (Searle, 1980). Ahora bien, hablar o escribir enunciados en un lenguaje, implica realizar un acto de habla y todo acto de habla está regido por las 
reglas del discurso en el que se profiere. Por ello, afirmar, preguntar, mandar, prometer, declarar y otras realizaciones lingüísticas son un tipo de acto llamado por Searle "actos ilocucionarios", es decir, aquellos que incluyen realizar algo y que llevan a la creación de discursos?

Todo tipo de discurso tiene sus reglas, incluido el discurso de "ficción". Así pues, según lo expuesto por Searle, en un discurso de "ficción" las reglas semánticas son alteradas o, en su defecto, suspendidas (Searle, 1979: 60); sin embargo, no por ello el discurso de "ficción" carece de reglas, simplemente requiere de un nuevo juego de reglas que se distinguen de las literales. El uso del lenguaje en tal o cual discurso nos lleva a la significatividad de los mismos.

En su análisis lógico sobre el discurso ficcional, Searle propone distinguir entre discursos literales o formales y discursos ficcionales. Los primeros los expone el autor como expresiones del tipo "serio" y los segundos del tipo "no-serio". Se debe resaltar que al decir que los discursos de ficción son "discursos no-serios" de ningún modo se pretende deslegitimar o tomar este tipo de discursos como falsos o "engañosos". Lo que se pretende resaltar, según Searle, es que cuando un autor de ficción realiza un acto ilocucionario del tipo "En la Plaza de Bolívar de Bogotá tenemos un sol radiante" no se compromete a que efectivamente esté haciendo buen tiempo en la Plaza de Bolívar de Bogotá y, de hecho, puede estar cayendo en el momento de la proferencia una tremenda tempestad. Que el discurso sea "no-serio" nada tiene que ver con que se quiera mentir al proferir un enunciado de ficción. Es preciso aclarar que Searle examinó el discurso de ficción en la literatura ${ }^{10}$. Sin embargo, existen otros discursos ficcionales en los cuales, los enunciados se comprometen con la verdad y son discursos serios, aun cuando no tengan cómo comprobarse empíricamente. Esto último es lo que ocurre en algunas teorías de la ciencia moderna. Con los enunciados científicos no se pretende mentir, aun cuando sean producto de supuestos hipotéticos y más adelante lleguen nuevos enunciados que los reemplacen, porque se

9 Dice Searle: “Asignemos ahora nombres a estos actos bajo la rúbrica general de actos de habla: a) Emitir palabras (morfemas, oraciones) = realizar actos de emisión. b) Referir y predicar $=$ realizar actos proposicionales. c) Enunciar, preguntar, mandar, prometer, etcétera = realizar actos ilocucionarios" (Searle, 1980: 32-33).

10 "En el habla de ficción «Sherlock Holmes» tiene referencia porque en el mundo de ficción existe realmente tal personaje, pero «La señora de Sherlock Holmes» carece de referencia porque no existe tal personaje en el mundo de ficción. El axioma de existencia cubre todo el campo: en el habla sobre el mundo real se puede hacer referencia solamente a lo que existe; en el habla sobre el mundo de ficción se puede hacer referencia a lo que existe en el mundo de ficción (además de las cosas y eventos del mundo real que incorporan las historias de ficción) (Searle, 1980: 87). 
comprueba que los anteriores no eran válidos. Tal es el caso del término "flogisto" que fue reemplazado por el "oxígeno" en la teoría de la combustión. Con lo cual no solo cambió el elemento, sino el término y el significado del mismo, así como los enunciados que los contenían.

En los enunciados de la física cuántica, de E. Schröndinger (1933), por ejemplo, se describe la evolución temporal de una partícula subatómica masiva de naturaleza ondulatoria y no relativista. Si bien no podemos comprobar tal supuesto, es claro que el enunciado mismo está lleno de significado y comprometido con la verdad en pos de brindar explicación al fenómeno en cuestión. Tal vez mañana no se hable de "partículas subatómicas" y aparezca un nuevo término con o sin referencia empírica, pero ello no desconoce el significado del enunciado, aun cuando deje de ser válido dentro de la teoría. El enunciado "Las partículas microscópicas incluyen a las partículas elementales", si bien está constituido con términos no referenciales dota de significado la teoría de sistemas de partículas en la mecánica cuántica, y lo hace porque sigue las reglas del discurso de "ficción" que se ha aceptado en la ciencia.

Ahora bien, la tesis central propuesta por Searle sobre el discurso de ficción descansa bajo el concepto de pretender. Un concepto que enmarca la intencionalidad del hablante (escritor o científico) al crear nuevos nombres y expresiones dentro de la pretensión de realizar de los actos de habla, con los cuales pretende explicar la realidad natural. Enunciados que dan origen a una nueva realidad: el mundo de la ficción: la realidad hipotética constituida por supuestos. Un científico que usa enunciados hipotéticos es similar al literato de ficción, puesto que están profiriendo convenientemente un acto ilocucionario; están pretendiendo (pretending-pretend) el acto en el juego del lenguaje seleccionado ${ }^{11}$. El escritor de ficción, para el autor de Actos de habla, está "participando en una no engañosa pseudo-representación que constituye la pretensión de volvernos a contar una serie de eventos (...). El autor de una obra de ficción pretende representar una serie de actos ilocucionarios, normalmente del tipo asertivo" (Searle, 1979: 65). Al igual que

11 Searle resalta que al decir que un escritor de ficción pretende-finge hacer un aserto es necesario distinguir entre dos sentidos muy diferentes de pretender. Veamos la diferencia con sus propias palabras: 'En un sentido de 'pretender', pretender ser o hacer algo que alguien no está haciendo es involucrarse en una forma de engaño, pero según el segundo sentido de 'pretender', pretender ser o hacer algo es involucrarse en una representación que es 'como si' uno estuviera haciendo o siendo la cosa y esto sin ninguna intención de engañar. Si yo pretendiera ser Nixon para engañar al servicio secreto y que me dejara entrar en la Casa Blanca, yo estoy 'pretendiendo' en el primer sentido de la palabra; si yo pretendiera ser Nixon como parte de un juego de roles, se trataría de 'pretender' en el segundo sentido. Ahora bien, en el uso ficcional de las palabras, se trata de 'pretender' en el segundo sentido lo que está en cuestión” (Searle, 1975: 64-65).

VERITAS, No 36 (Abril 2017) 
lo hace el científico quien pretende representar hipotéticamente una parte de la realidad con el mismo tipo de actos de habla.

Para Searle, el incumplimiento de las reglas verticales hace posible la ficción, y esta, a través de una serie de convenciones extra-lingüísticas y no semánticas, quebranta la relación que sí debe cumplir el texto serio, esto es, la relación entre el texto y la realidad. A estas reglas "quebrantadoras" Searle las llama "horizontales". Ellas hacen posible el discurso de ficción, pues suspenden los "requerimientos" aceptados en el discurso serio, dando paso a un discurso parasitario (parasitic), que se sostiene finalmente gracias a un discurso serio. En el caso de la ciencia, tal discurso de "ficción" está contenido en el discurso serio y por ello es difícil detectarlo. Searle escribe, a propósito de las convenciones horizontales, que éstas: "suspenden los requerimientos normales establecidos por esas reglas. Estas convenciones horizontales no son reglas de significado; no pertenecen a la competencia semántica del hablante “(...) Lo que hacen, más bien, es capacitar al hablante para usar las palabras con sus significados literales sin asumir los compromisos que requieren normalmente esos significados" (Searle, 1979: 66-67) ${ }^{12}$. De ahí que Searle diga que los discursos de ficción son indistinguibles de los actos de proferencia del discurso literal. El escritor de ficciones hace como si realizará actos ilocucionarios "exitosos", pero en ese pretender quebranta las convenciones normales dejando entrar en escena la riqueza de la creación artística, la imaginación y en el caso de la ciencia la realidad hipotética. Él es quien da inicio a la "ficción" bien sea en la ciencia o en la literatura.

$\mathrm{Al}$ respecto, Umberto Eco advierte en Lector in fabula, respaldando la tesis de Searle, que:

Es cierto que un texto narrativo es una serie de actos lingǘsticos que "fingen" ser aserciones sin exigir, no obstante, que se crea en ellas ni proponer una prueba de las mismas; pero se comporta así respecto de la existencia de los personajes imaginarios con que opera: en cambio, no excluye que, alrededor de las aserciones ficticias, que va devanando, por el contrario, se alineen otras, no ficticias que, por el contrario, encuentran sus condiciones de felicidad en la fuerza con que el autor las sostiene y en las pruebas con que (tras la apariencia de la parábola narrativa) intenta apuntalar lo que afirma

12 "Las pretendidas ilocuciones que constituyen una obra de ficción son posibles por la existencia de una serie de convenciones que suspenden la normal operación de las reglas que relacionan actos ilocucionarios y mundo. En este sentido, usando la jerga de Wittgenstein, contar historias es realmente un juego independiente de lenguaje; para ser jugado requiere otra serie separada de convenciones, a pesar de que estas convenciones no son reglas de significado; y el juego de lenguaje no está en relación de igualdad con juegos de lenguaje ilocucionarios, pero es parásito de ellos" (Searle, 1975: 66-67). 
sobre la sociedad, la psicología humana y las leyes de la historia (Eco, 1987: $71)$.

Así pues, el instinto de Frege iba por buen camino al inferir el hecho de que hacemos enunciados de identidad fácticamente informativos usando nombres propios, a lo que habría que agregar que no solo serían informativos, sino explicativos. Discursos que poseen sentido. Sin embargo, Frege estaba equivocado al suponer que este sentido es tan claro como una descripción definida, puesto que en la ciencia vemos que no lo es. Su ejemplo de «la estrella de la mañana-la estrella de la tarde», le llevó a extraviarse, porque, aunque el sentido de estos nombres está claro, estas expresiones no son nombres propios paradigmáticos, sino que están en la línea fronteriza entre las descripciones definidas y los nombres propios.

Frege desconoció al hablante y la fuerza ilocucionaria que profiere en tales expresiones, desconoció, además, el significado dado en el uso del lenguaje, en las convenciones, además de buscar, como el resto de la filosofía de la época, una respuesta única e inequívoca a tales cuestiones, lo que Searle denomina el error de la filosofía, el cual consiste en "[...] suponer que a menos que haya una respuesta correcta e inequívoca, el concepto de referencia carece de valor" (Searle, 1980: 37). Para Searle, el correlato lingüístico de tales expresiones se da en el contexto, como lo expuso Frege, pero se aleja de este al exponer, que, además, “[...] la expresión referencial solo cuenta como referencial si se dice algo mediante ella" (Searle, 1980: 34) y todos los enunciados de la ciencia logran tal cometido.

\section{El discurso de "ficción" como un mundo de significados posibles}

"Pretender" es un verbo intencional. Uno de esos verbos que contienen el concepto de intención dentro de ellos. No puede decirse que alguien ha pretendido hacer algo si no ha tenido la intención de pretender hacerlo. Así nuestra primera conclusión aparece: el criterio identificativo para saber si un texto es o no un discurso de "ficción" debe necesariamente estar en las intenciones ilocucionarias del autor. En la ciencia, la intención de los enunciados aparece en la comunidad científica a la hora de establecer el término que permite explicar los fenómenos, de la misma manera que sucede en la literatura de "ficción". No hay alguna propiedad textual, sintáctica o semántica, que identifique un texto como un discurso de "ficción" si no hay intencionalidad de ello. Los enunciados construidos con términos o nombres de "ficción" solo son comprensibles para los hablantes cuando se devela la intencionalidad que el autor ha impregnado en estos. El uso del lenguaje para asignar intencionalmente la función de estatus a 
los términos de la ciencia permite que la comunidad y la sociedad reconozcan que tales enunciados pertenecen a la ciencia, aun cuando carezcan de referente y se tomen como términos de "ficción".

Lo que convierte un discurso en una obra de ficción es, por decirlo de alguna manera, la postura ilocucionaria que el autor toma con respecto a ella, y esa postura es cuestión de las complejas intenciones ilocucionarias que el autor tiene cuando profiere o escribe el enunciado. Las pretendidas ilocuciones que constituyen una obra de ficción son posibles por la existencia de una serie de convenciones que suspenden la normal operación de las reglas que relacionan actos ilocucionarios y mundo.

En este sentido, Searle sigue a Wittgenstein al afirmar que contar historias es realmente un juego independiente de lenguaje; al igual que lo serían los enunciados de la física cuántica o de la química moderna. Juegos que para ser jugados requieren de otra serie de convenciones que difieren de las que usamos en el discurso literal. A pesar de que estas convenciones no son reglas de significado y el juego de lenguaje no está en relación de igualdad con juegos de lenguaje ilocucionarios, sí requiere de reglas que lo regulen, en las cuales aparecen nuevos significados de las pretensiones proferidas dentro de la nueva realidad creada por el discurso. En este sentido, el discurso de "ficción" se convierte en un parásito del discurso expresado en los actos de habla. Un parásito que constituye una nueva realidad gracias la intencionalidad del escritor. Allí aparece explícita nuestra segunda conclusión: todo enunciado de ficción está regulado por las reglas del juego que el discurso de ficción exige y los hablantes deben comprometerse con tales reglas para determinar el significado y la aceptabilidad de tal enunciado.

Una tercera conclusión nos lleva a circundar por el tema de la intencionalidad en los actos de habla ilocucionarios. El uso del lenguaje y la fuerza ilocucionaria de los actos de habla del tipo asertivos hacen posible que términos sin referencia posean significatividad. El discurso de "ficción" de las teorías científicas está comprometido con el valor de verdad de una realidad hipotética, cuyo propósito es brindar explicaciones a los fenómenos naturales.

Ahora bien, además de la intención, existe otro elemento fundamental para comprender el discurso de "ficción" como un mundo posible o como explicaciones de los fenómenos de la realidad: la función de estatus. Así florece la cuarta conclusión. Para Searle (1995) la intencionalidad de los hablantes permite asignar de manera colectiva ciertas funciones de estatus. En el discurso de "ficción" de los enunciados de supuestos hipotéticos que sustentan las teorías de la ciencia, las referencias y nombres de "ficción" son funciones asignadas por los hablantes (científicos). No podrían proferirse nombres como "átomos", "oxígeno", "molécula", si los hablantes no se comprometen con el juego de las reglas que el discurso exige. Es 
decir, si Lavoisier, Dalton o Schrödinger no hubiesen usado los términos intencionalmente. La asignación de estatus a términos como: "oxígeno", "partícula" o "átomo" exige a la comunidad aceptar su significación dentro de la comunidad científica. Los términos acaban por ser aceptados, usados y reconocidos institucionalmente en la ciencia por la pragmática del lenguaje.

"A veces, la asignación de funciones tiene que ver con nuestros propósitos inmediatos, ya sean prácticos, gastronómicos, estéticos, didácticos, o cualesquiera otros" (Searle, 1995: 38). En el caso de la asignación de funciones de estatus los hablantes están comprometidos a través del juego de reglas del discurso a considerar el discurso de "ficción" dentro del discurso científico y pretender que este haga parte del discurso serio, aun cuando en el análisis se logre diferenciar del discurso literal. La asignación de funciones agentivas a los términos que constituyen el fundamento de las teorías, aun cuando estos carezcan de referente, dotan de significado a los enunciados básicos que las constituyen. Las palabras por sí mismas no logran dar cuenta del significado, por ello, el hablante (científico) debe elaborar discursos para tal fin.

Los enunciados de "ficción" en la ciencia cuentan con su propio significado, un significado que produce una realidad hipotética, un significado que no depende de la contrastación empírica con el mundo para verificar el valor de verdad. Su significatividad está dada por la intencionalidad del científico que asigna funciones de estatus al término con la pretensión de explicar el fenómeno físico. El uso del lenguaje permite crear teorías basadas en supuestos para explicar fenómenos físico-químicos del mundo. Teorías no contrastables con los hechos fácticos, las cuales sirven de modelo para la comprensión de los mismos.

Ahora bien, un quinto elemento que permite reconocer los nombres de "ficción" como un discurso objetivo y propio en la ciencia, así como ocurre en la literatura, es el hecho de que el discurso parasitario o no- serio, como lo denominó Searle, no surge de la nada, sino que tiene como punto de partida los hechos brutos que constituyen el mundo. Un "Quijote" o un "Macondo" así como los términos "oxígeno" o "flogisto" carecen de referente en el mundo, pero permiten representar simbólica e hipotéticamente parte de este. Tales nombres surgen de fenómenos u objetos que conforman la realidad de los hechos brutos y dan cuenta de ellos.

En este sentido, siguiendo a Searle, podemos inferir que el lenguaje y la mente crean discursos que hacen posibles o nuevas realidades, como el caso de la realidad social, la realidad de la literatura de ficción y para lo que nos convoca la realidad hipotética en la ciencia, la cual pretende la comprensión de la realidad de los fenómenos enigmáticos del universo. Los 
juegos del lenguaje permiten nuevos discursos con sus propias reglas y dentro de ellos es posible alcanzar significatividad.

Así pues, en la discusión anterior se ha explorado la cuestión sobre lo que posibilita a un autor de teorías científicas para utilizar las palabras y expresiones no referenciales en un discurso, cuyos enunciados, rompe los cánones trazados por la teoría de la demarcación. El uso de términos sin referencia no hace menos válidos o veraces los enunciados de las teorías científicas, producto de supuestos hipotéticos, ni se puede afirmar que tales teorías carezcan de significado. Por el contrario, el uso del lenguaje en el juego del discurso de "ficción" en los enunciados de la ciencia dota a tales términos de significado a partir de la intencionalidad del hablante, como ocurre en cualquier otro discurso, ya que la pragmática del lenguaje es la que hace posible la significatividad en cualquier discurso.

Se ha expuesto, además, cómo la cuestión de la referencia y el significado es abordada por Searle, siguiendo la teoría de los juegos del lenguaje de Wittgenstein, de manera diferente a la que había realizado la tradición filosófica, lo cual lo lleva a forjar un camino en el giro lingüistico al exponer una nueva concepción de la referencia como acto de habla. En otras palabras, el significado de un discurso se logra en el uso del lenguaje, según el contexto en el que se profiere y con la emisión de actos ilocucionarios. Una teoría que se aplica no solo a los discursos literales o formales, sino a los discursos de "ficción", no solo de la literatura, sino de las ciencias modernas, superando con ello la concepción de la significatividad en términos de la referencia, tal y como lo planteaba la tradición filosófica.

En tal sentido, se puede afirmar que los actos de habla como las aserciones tienen significado en el marco de la proferencia del enunciado mismo, por ello, los enunciados de la ciencia que no tienen referente empírico sustentan su significado en el acto de habla mismo. El uso del término y la convención de su uso dan vida al mismo y otorgan significado a los enunciados básicos que sustentan las teorías en la ciencia moderna. En palabras de Searle, "llevar a cabo un acto de proferencia con la intención de invocar las convenciones horizontales es la que constituye la pretendida realización del acto ilocucionario" (Searle, 1979: 66-67); y si se cumplen tales convenciones en un discurso la significatividad se logra no importando el tipo de discurso que sea proferido.

\section{REFERENCIAS}

-Ayer, A. (1983). La Filosofía del siglo XX. Barcelona: Crítica.

-Carnap, R. (1998). Filosofía y sintaxis lógica. México: UNAM.

-Eco, U. (1987). Lector in fabula. La cooperación interpretativa en el texto narrativo. Barcelona: Lumen. 
-Fogelin, R. (1995). Wittgenstein. London: Routledge \& Kegan Paul Ltd.

-Frege, G. (2005). Sobre sentido y referencia. En L. Valdés Villanueva (ed.), La búsqueda de significado (pp. 84-111). Madrid: Tecnos.

-Goodman, N. (1990). Maneras de hacer mundos. Madrid: Visor.

-Goodman, N. (1995). De la mente y otras materias. Madrid: Visor.

-Kuhn, T. (2004). La estructura de las revoluciones científicas. México: Fondo de Cultura Económica.

-Platón (1987). Crátilo. En Platón, Diálogos II. Madrid: Gredos.

-Popper, K. (1981). Panorama de algunos problemas fundamentales. En La concepción política de la filosofía (pp. 149-171). Madrid: Alianza.

-Rodríguez, A. (2015). Searle y la posibilidad de derivar un "Debe" de un "Es". Escritos, 23(50), 213-229.

-Rorty, R. (2001). La filosofía y el espejo de la naturaleza. Madrid: Cátedra.

-Russell, B. (1966). Lógica y conocimiento. Madrid: Taurus.

-Russell, B. (2005). Descripciones. En L. Valdés Villanueva (ed.), La búsqueda de significado (pp. 50-59). Madrid: Tecnos.

-Saer, J. (1997). El concepto de ficción. Buenos Aires: Seix Barral.

-Santamaría, F. (2007). Nombres, significados y mundos. Salamanca: Universidad Pontificia de Salamanca.

-Santamaría, F. (2011). El nombrar, la necesidad y la identidad. Kripke y la teoría de la referencia. Escritos, 19(43), 401-419.

-Searle, J. (1975). The logical status of Fictional Discourses. En New Literary History. Baltimore: The Johns Hopkins University Press.

-Searle, J. (1979). Expression and Meaning. Studies in the Theory of Speech Acts. Cambridge: Cambridge University Press.

-Searle, J. (1980). Actos de habla. Un ensayo en la filosofía del lenguaje. Cambridge: Cambridge at the University Press.

-Searle, J. (1995). The Construction of Social Reality. New York: The Free Press.

-Searle, J. (2010). Making the Social World. The Structure of Human Civilization. Oxford: University Press.

-Shröndinger, E. (1933). Mémoires sur la mécanique ondulatoire. Paris: Félix-Alcan.

-Wittgenstein, L. (1988). Investigaciones filosóficas. Barcelona: UNAM/Crítica.

Sumario: Introducción; 1. El discurso de "ficción" en la ciencia; 2. El significado en la pragmática del lenguaje; 2.1. El problema: nombre, objeto y referencia; 2.2. La significatividad en los juegos del lenguaje; 3 . Referencialidad y significatividad en Searle; 4. Actos ilocucionarios y significatividad en los discursos; 5. El discurso de "ficción" como un mundo de significados posibles; Referencias. 